\title{
The hepatoprotective effect of gooseberry and black mulberry extracts against carbon tetrachloride-induced liver injury in rats
}

\author{
Shimaa Elmasry ${ }^{1 *}$ (10) and Mahmoud Moawad ${ }^{2}$
}

\begin{abstract}
Background: Liver is the vital organ of the human body responsible for nutrition, immunity, and metabolism. Carbon tetrachloride $\left(\mathrm{CCl}_{4}\right)$ is an environmental pollutant that causes hepatotoxicity. This study aimed to evaluate the possible hepatoprotective effect of aqueous and ethanolic extracts of gooseberry and black mulberry on liver injury induced by $\mathrm{CCl}_{4}$ in rats.

Results: $\mathrm{CCl}_{4}$ caused significant $(P \leq 0.05)$ elevation in the liver function tests and hydroxyproline (a major marker of fibrosis); also, there was a significant increase in the hepatic malondialdehyde (MDA), nitric oxide (NO), and plasma inflammatory biomarkers, whereas a significant decrease in the hepatic reduced glutathione (GSH), glutathione peroxidase (GPX), and plasma adiponectin levels was observed in the $\mathrm{CCl}_{4}$-treated group compared with control. These results were also confirmed by histological examination of liver tissue. Administration of gooseberry or black mulberry extracts alone decreased the hepatic level of hydroxyproline, ameliorated the antioxidant/oxidant status in liver tissue, and decreased the pro-inflammatory cytokines compared to normal control. Treatment with the tested extracts along with $\mathrm{CCl}_{4}$ was effectively able to ameliorate the abovementioned imbalances induced by $\mathrm{CCl}_{4}$ and protect the liver tissue.
\end{abstract}

Conclusion: These results indicate that gooseberry and black mulberry extracts have a hepatoprotective effect against carbon tetrachloride-induced liver injury in rats.

Keywords: Carbon tetrachloride, Liver injury, Liver fibrosis, Gooseberry, Black mulberry, Physalis peruviana L., Morus nigra

\section{Background}

Liver is the largest gland in the body and the key organ of immunity, nutrition, and metabolism (Ahmed, Eldemardash, \& Ali, 2019). Hepatic damage caused by chemicals or infectious agents is associated with a disturbance of the metabolic functions of liver and may lead to progressive liver fibrosis, cirrhosis, and liver failure (Cullen, 2005). Carbon tetrachloride $\left(\mathrm{CCl}_{4}\right)$ is a common toxin that is widely used for experimental induction of liver injury and fibrosis

\footnotetext{
*Correspondence: shimaa_elmasry33@yahoo.com

'Department of Biochemistry and Nutrition, Faculty of Women for Arts,

Science and Education, Ain Shams University, Cairo, Egypt

Full list of author information is available at the end of the article
}

(Weiler-Normann, Herkel, \& Lohse, 2007). The principal causes of $\mathrm{CCl}_{4}$-induced hepatic injury and fibrosis are increased lipid peroxidation, generation of free radicals, and the depletion of antioxidant status (Shahidi \& Zhong, 2010). Accordingly, antioxidant supplementation can reduce the risk of liver injuries and offer insights into delaying or preventing the occurrence and development of hepatic fibrosis (Deng et al., 2012). Rajesh and Latha (2004) indicated that various herbal extracts may protect liver against $\mathrm{CCl}_{4}$ induced oxidative stress by reverse the increased levels of lipid peroxidation and enhancing the decreased activities of antioxidant enzymes. Cape gooseberry (Physalis peruviana L.) is belonging to the 
family Solanaceae and genus Physalis, it is known locally in Egypt as Harankash and in English-speaking countries as goldenberry, and it has many medicinal and edible uses as a promising fruit (Ramadan, 2011). The fruits are succulent golden spheres the sizes of marbles, each fruit contains about 100-200 small seeds (Luis, Claudia, Eduardo, \& Misael, 2011). Gooseberry is a widely used herb in folk medicine for several diseases. It was reported that Physalis peruviana L. have various bioactive compounds, some of which have a strong antioxidant property and prevent peroxidative damage of liver cells (Al-Olayan et al., 2014). Wu et al. (2006) illustrated that the ethanolic extract of gooseberry fruit had higher antioxidant properties than the aqueous extract. The antioxidant properties associated with the fruits are due to their high levels of polyphenols, vitamins A ( $\alpha$-carotene, $\beta$ carotene, and $\beta$ cryptoxanthin), and vitamin $C$. The specific active constituents of Physalis peruviana $\mathrm{L}$. are Physalins A, B, D, F, and glycosides, which show anticancer activity (Wu et al., 2004). Physalis peruviana L. contains also 28-hydroxywithanolide, withanolides, phygrine, kaempferol, quercetin diglycosides, and triglycosides (Arun \& Asha, 2007). Some of these active components were previously reported to have antitumor, cytotoxic inhibition of the ubiquitinproteasome pathway (Ausseil et al., 2007); immunomodulatory (Soares et al., 2006), anti-inflammatory, and antiallergic activities (Lee, Pan, Chen, \& Chen, 2008). Black mulberries (Morus nigra) are belonging to the family Moraceae. Its flavonoids have strong antioxidant activity. The fruits are used in medicine against inflammation and to stop bleeding, the bark is used for toothache, and the leaves for treating snakebites and used as an antidote to poison (Feng et al., 2015). M. nigra is rich in essential fatty acids as linoleic acid, polyphenols, flavonoids, and anthocyanins, which are accountable for its color (Ross \& Kasum, 2002; Salcedo, Sendra, Barrachina, Martínez, \& Hernández, 2016). Anthocyanins extracted from mulberry has been reported to present neuroprotective (Kang et al., 2006) and antitumor activity (Huang, Shih, Chang, Hung, \& Wang, 2008). It has been also shown that $M$. nigra has a protective action against oxidative damage to membranes and biomolecules (Memon, Memon, Luthria, Bhanger, \& Pitafi, 2010). The flavonoids compound of black mulberry has been shown to have hepatoprotective activity as previously reported (Mallhi, Qadir, Khan, \& Ali, 2014).

Hence, the present study was aimed to investigate the possible hepatoprotective effects of gooseberry and black mulberry (water and ethanolic extracts) against $\mathrm{CCl}_{4}$-induced hepatic injury and fibrosis in male albino rats.

\section{Methods}

\section{Chemicals and plant materials}

Carbon tetrachloride $\left(\mathrm{CCl}_{4}\right)$ was purchased from Sigma for chemicals company, Cairo. Egypt. The mature and fresh fruits of gooseberry and black mulberry were purchased from the local markets of Cairo, Egypt. The fruits were cleaned, oven-dried at temperature $50^{\circ} \mathrm{C}$, then were ground in a mortar. For the preparation of water and ethanolic extracts, $250 \mathrm{~g}$ of dried plant fruits were mixed with 1000-mL solvents [water and ethanol (95\%)] in dark-colored bottles and extracted at room temperature overnight. The resulted suspension was filtered through Whatman filter paper and the operation was repeated 2 times for re-extraction, then the solvent was removed by using a rotary evaporator at $40{ }^{\circ} \mathrm{C}$. The extracts were kept at $-8{ }^{\circ} \mathrm{C}$ until use.

\section{Measurement of total flavonoids, total polyphenols, and total antioxidants activity}

Total flavonoids in water and ethanolic extracts of gooseberry and black mulberry were assessed according to Sakanaka, Tachibana, and Okada (2005). Flavonoids were determined as quercetin from a calibration curve (Merfort et al., 1997) and expressed as $\mathrm{mg} / \mathrm{g}$ of the extract. Total phenolic content was determined as described by Kähkönen et al. (1999), using the FolinCiocalteu procedure and expressed as $\mathrm{mg}$ gallic acid equivalents (GAEs)/g of the extract. The free radical scavenging activity (total antioxidant activity) of extracts was measured by $\alpha, \alpha$-diphenyl- $\beta$ - picryl- hydrazyl (DPPH) according to Brand-Williams, Cuvelier, and Berset (1995). Radical scavenging activity was expressed as a percentage of inhibition/g of the extract and was calculated using the formula: \% Radical scavenging Activity = [(control OD - sample OD)/control OD] × 100 .

\section{Laboratory animals}

Adult male Sprague-Dawley rats weighing 150-160g were used for this study, and all were kept in the animal house of the Medical Research Center, Faculty of Medicine, Ain Shams University, Cairo, Egypt. The animals were housed in stainless steel cages and maintained under standard laboratory conditions (temperature $25 \pm$ $5^{\circ} \mathrm{C}$ ) with dark and light cycle $(12 / 12 \mathrm{~h})$. The acclimatization period lasted for 7 days. All animals were fed with a standardized pellet diet and water ad libitum throughout the experimental period (5 weeks). The protocol of this study was approved by the research ethical approval committee of the Medical Research Center, Ain Shams University.

\section{Experimental design}

The concentrated extracts were dissolved in distilled water immediately before use and administered to rats 
in a dose of $250 \mathrm{mg} / \mathrm{kg}$ b.wt according to Taj, Khan, Sultana, Ara, and Ehteshamul-Haque (2014).

Sixty rats were randomly divided into 10 groups of 6 animals each. Group 1 (control): orally received $0.5 \mathrm{ml}$ corn oil/kg b.wt, 3 times a week. Group $2\left(\mathrm{CCl}_{4}\right)$ : the animals were orally given $\mathrm{CCl}_{4}\left(1 \mathrm{ml} / \mathrm{kg}\right.$ body weight $\mathrm{CCl}_{4} /$ corn oil, 1:1 v/v), 3 times a week. Group $3(\mathrm{GW})$ : were given orally water extract of gooseberry $(250 \mathrm{mg} / \mathrm{kg}$ b.wt) daily. Group 4 (GE): were orally given ethanolic extract of gooseberry (250 mg/kg b.wt) daily. Group 5 $(\mathrm{MW})$ : were orally given water extract of black mulberry (250 mg/kg b.wt) daily. Group 6 (ME): were orally given ethanolic extract of black mulberry $(250 \mathrm{mg} / \mathrm{kg}$ b.wt) daily. Groups 7, 8, 9, and 10 were orally given $\mathrm{CCl}_{4}(1$ $\mathrm{ml} / \mathrm{kg}$ body weight $\mathrm{CCl}_{4} /$ corn oil, $\left.1: 1 \mathrm{v} / \mathrm{v}\right), 3$ times a week, and daily received $250 \mathrm{mg} / \mathrm{kg}$ b.wt of GW, GE, MW, and ME extracts, respectively. The animals were observed daily for mortality and the body weight of all rats was recorded weekly.

At the end of the 5th week, all rats were sacrificed under ether anesthesia. Blood samples were collected from the hepatic portal vein into heparinized tubes and centrifuged at $3000 \mathrm{rpm}$ for $30 \mathrm{~min}$ at $4^{\circ} \mathrm{C}$; plasma samples were stored at $-20{ }^{\circ} \mathrm{C}$ for further assessment. The liver tissues were immediately removed, washed in cold saline, dried on filter paper, and weighed using an electronic balance. Parts of the liver tissue were immediately fixed in 10\% neutral phosphate-buffered formalin for histopathological study. Other parts were used for tissue homogenate preparation, in which, liver tissue was homogenized in $5 \mathrm{ml}$ cold buffer (i.e., $50 \mathrm{mM}$ potassium phosphate, pH 7.5. $1 \mathrm{mM}$ EDTA) per gram tissue. The homogenate was centrifuged at $5000 \mathrm{rpm}$ for $20 \mathrm{~min}$; the supernatant was removed and kept at $-80^{\circ} \mathrm{C}$ till processed.

\section{Biochemical assays}

Plasma alanine transaminase (ALT) and aspartate transaminase (AST) activities were determined colorimetrically according to Murray (1984); plasma alkaline phosphatase (ALP) activity was measured by colorimetric method kit as described by Belfield and Goldberg (1971). Plasma alpha-fetoprotein (AFP) level was estimated by the immune-enzymatic colorimetric method according to Acosta (1983). Hepatic hydroxyproline was measured using commercial diagnostic kit K555-100 (BioVision Research Products, CA, USA). Reduced glutathione (GSH) was determined colorimetrically according to Beutler, Duron, and Kelly (1963). Glutathione peroxidase (GPx) was assessed by UV method kit as described by Paglia and Valentine (1967). Malondialdehyde (MDA) and nitric oxide (NO) were determined by the colorimetric method kits according to Montgomery and Dymock (1961) and Ohkawa, Ohishi, and Yagi (1979) respectively. Plasma interferon-gamma (IFN $\gamma$ ) was assessed using Rat IFN-gamma ELISA Kit, RayBiotech, USA. Tumor necrosis factor-alpha (TNF- $\alpha$ ), nuclear Factor $\kappa B(N F-\kappa B)$, and adiponectin were determined using Rat ELISA kit, MyBioSource, USA.

\section{Histopathological examination of liver lesions}

Liver specimens were fixed in 10\% formalin solution and processed routinely for paraffin embedding. Sections (4$\mu \mathrm{m}$-thick) were deparaffinized, stained with hematoxylin and eosin solutions (H\&E), and examined under the light microscope (Bancroft, Stevens, \& Turner, 1996).

\section{Statistical analysis}

The data were analyzed using SPSS 26 for windows. All variables were compared using one-way analysis of variance (ANOVA) followed by LSD post hoc test. $P \leq 0.05$ was considered statistically significant (Levesque, 2007).

\section{Results}

The data presented in Table 1 illustrate the values of total flavonoids as mg quercetin equivalent $(\mathrm{QE}) / \mathrm{g}$ of the extract and total phenols as mg gallic acid equivalents (GAEs)/g of the extract, as well as total antioxidant capacity indicated by the 1,1-diphenyl-2-picryl hydrazyl DPPH free radical scavenging activity. Results showed that the GW extract has the highest level of total flavonoids. Concerning total phenols, the highest level was found in the MW extract. The ethanolic extracts of gooseberry (GE) have more antioxidant capacity than other extracts.

As shown in Figs. 1, 2, and 3, administration of $\mathrm{CCl}_{4}$ caused a significant $(P<0.05)$ decrease in the body weight and increase in liver weight and relative liver weight (hepatosomic index) of rats. Gooseberry and black mulberry extract markedly reduced the liver weight and hepatosomic index in treated groups when compared with the $\mathrm{CCl}_{4}$ group.

The results presented in Table 2 indicated that rats treated with $\mathrm{CCl}_{4}$ have significantly $(P<0.05)$ elevated levels of plasma ALT, AST, ALP, and AFP compared to the normal control group. Likewise, the collagen deposition as evidenced by hepatic hydroxyproline in $\mathrm{CCl}_{4}$ treated rats was significantly higher than the normal level of a control group. The level of liver enzymes in groups that were administered with the tested extracts alone still not different from the control group although they showed a marked decrease in the liver hydroxyproline level. However, treatment with gooseberry and black mulberry extracts along with $\mathrm{CCl}_{4}$ significantly reduced the elevated levels of ALT, AST, and ALP (the most reduced level was found in the $\mathrm{CCl}_{4}+\mathrm{ME}$ group), alfa fetoprotein, and hydroxyproline (lowest level was found in $\mathrm{CCl}_{4}+\mathrm{GE}$ group) compared to the hepatotoxin group. 
Table 1 Total flavonoids, phenols, and antioxidant capacity of gooseberry and black-mulberry extracts

\begin{tabular}{|c|c|c|c|c|c|c|}
\hline \multirow[t]{2}{*}{ Extract type } & \multicolumn{2}{|c|}{$\begin{array}{l}\text { Total flavonoids (mg as QE/1 } \mathrm{g} \text { of } \\
\text { extract) }\end{array}$} & \multicolumn{2}{|c|}{$\begin{array}{l}\text { Total phenols ( } \mathrm{mg} \text { as GAEs } / 1 \mathrm{~g} \text { of } \\
\text { extract) }\end{array}$} & \multicolumn{2}{|c|}{$\begin{array}{l}\text { Total antioxidants capacity (\% of inhibition } / 1 \\
\mathrm{~g} \text { of extract) }\end{array}$} \\
\hline & Gooseberry & Black-mulberry & Gooseberry & Black-mulberry & Gooseberry & Black-mulberry \\
\hline Water extract & 34.13 & 27.22 & 29.11 & 32.11 & 78.92 & 76.08 \\
\hline Ethanol extract & 30.06 & 16.62 & 25.31 & 31.22 & 80.01 & 75.32 \\
\hline
\end{tabular}

A significant decline $(P<0.05)$ was observed in the hepatic GSH level and GPx enzyme activity after $\mathrm{CCl}_{4}$ treatment compared to normal control. In contrast, a marked increase in MDA and NO was found in the liver of $\mathrm{CCl}_{4}$-treated animals. Interestingly, the oxidant/antioxidants status was improved with the treatment of healthy rats by gooseberry and black mulberry extracts compared to normal control rats (GE group showed the most ameliorated effect). Administration of gooseberry and black mulberry extracts along with $\mathrm{CCl}_{4}$ resulted in a significant increase in hepatic GSH and GPx (highest level was found in GW group), and reduction in MDA and NO (lowest level was found in GE group) comparable to the hepatotoxic group (Table 3).

As illustrated in Table 4, high levels of proinflammatory cytokines (IFN $\gamma$ and TNF- $\alpha$ ) and the transcription factor nuclear factor- $\kappa B(N F-\kappa B)$ were detected in the plasma of rats after $\mathrm{CCl}_{4}$ treatment. Also, $\mathrm{CCl}_{4}$ caused a significant decline in serum concentration of the anti-inflammatory adipocyte-derived adiponectin comparing to control rats. Treatment of rats with the tested extracts alone significantly decreased the levels of pro-inflammatory cytokines when compared to the control group. The elevated levels of IFN $\gamma$, TNF- $\alpha$, and NF- $\mathrm{kB}$ induced by $\mathrm{CCl}_{4}$ were significantly $(P<0.05)$ alleviated, while the decreased level of adiponectin increased markedly after treatment with gooseberry and black mulberry extracts.

As indicated by H\&E staining of liver tissue (Fig. 4), samples from the normal control group and treated groups (GW, GE, MW, and ME) showing normal architecture with the presence of central vein surrounded by hepatocytes which separated by blood sinusoids, the hepatocytes are polyhedral shape with a central rounded nucleus, respectively. On the other hand, significant destruction of hepatic architecture, apparent portal fibrosis, activation of hepatic stellate cells as well as periportal aggregations of inflammatory cells, and congestion of blood vessels were identified in the liver tissue of rats after 5 weeks of $\mathrm{CCl}_{4}$ administration. The liver tissue of $\mathrm{CCl}_{4}$-intoxicated rats that were treated with GW showed improvement in the morphology of liver comparing to the $\mathrm{CCl}_{4}$ group with few lymphocyte infiltrations and less periportal fibrosis. $\mathrm{CCl}_{4}+\mathrm{GE}$ group showed the most improvement in hepatic architecture near to control group with few lymphocyte infiltrations and no fibrosis. Amelioration of hepatocytes with some fibrosis and few lymphatic infiltrations around blood vessels was shown in the liver tissue from the $\mathrm{CCl}_{4}+\mathrm{MW}$ group, while treatment with $\mathrm{ME}$ along with $\mathrm{CCl}_{4}$ cause improvement in the morphology of liver tissue with few lymphocyte infiltrations and less periportal

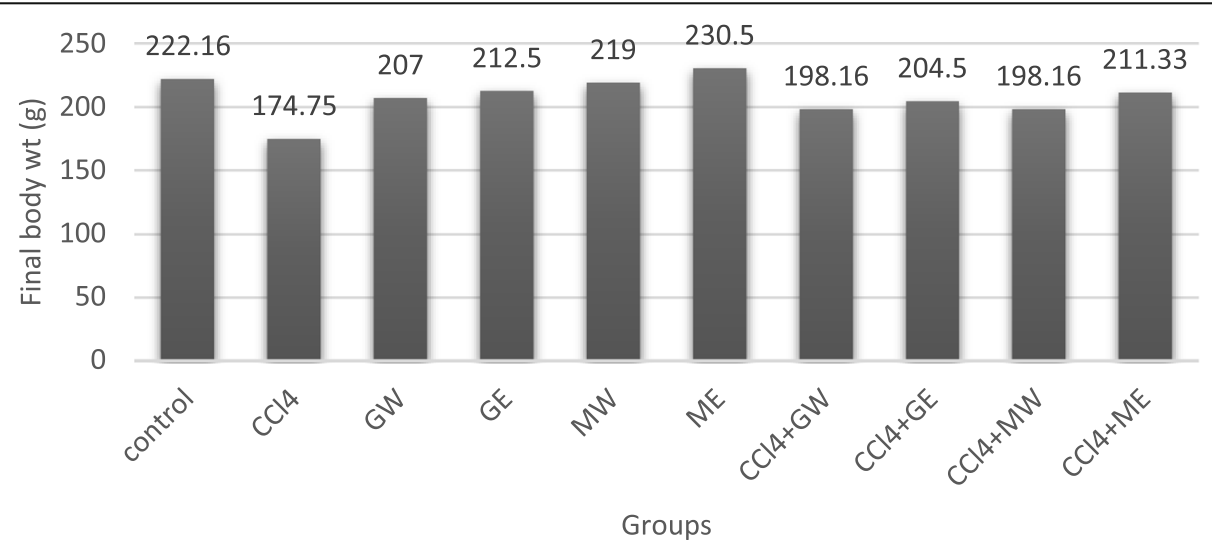

Fig. 1 Final body weight (g). Values are expressed as means $\pm S E, n=6(P \leq 0.05)$ 


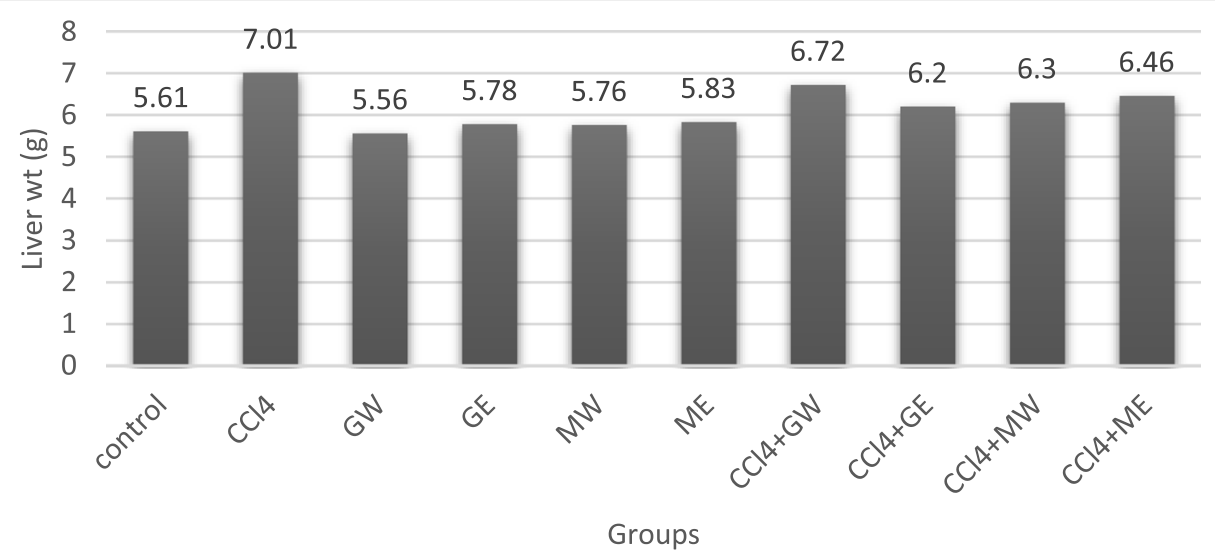

Fig. 2 Liver weight (g). Values are expressed as means $\pm S E, n=6(P \leq 0.05)$

fibrosis in comparison with $\mathrm{CCl}_{4}$ group. The histopathological findings are summarized in Table 5.

\section{Discussion}

Since ancient times, natural plant products have been used as a remedy and protection from various diseases. Therefore, we sought to investigate the effect of aqueous and ethanolic extracts of gooseberry and black-mulberry as a possible hepatoprotective agent in the $\mathrm{CCl}_{4}$-induced hepatic injury. Our results indicated that administration of aqueous and ethanolic extracts of both berries at a daily dose of $250 \mathrm{mg} / \mathrm{kg}$ b.wt for 5 weeks induced hepatic protection against $\mathrm{CCl}_{4}$ and was associated with reduced the biomarkers of liver injury and oxidative stress and reduced cytokine content associated with inflammation and ameliorated liver architecture. It is clear from Table 1 that GW, GE, MW, and ME possesses potent total antioxidant activity and contain reasonable amounts of total flavonoids and phenols, with GW and GE have the highest level of antioxidant capacity and total flavonoids, while MW and ME have the highest level of total phenols. This could be attributed to the antioxidant activity of these natural extracts. Previous studies also have demonstrated that gooseberry and black mulberry extracts exhibit many bioactive features including antioxidant and anti-inflammatory properties due to the presence of large amounts of phenolic compounds and flavonoids. The qualitative analysis of Physalis peruviana L. ethanolic extract performed by Sathyadevi and Subramanian (2015) revealed the presence of biologically active compounds such as phenols, flavonoids, glycosides, sterols, saponins, tannins, lactones, and alkaloids. The fruit extract was also found to contain significant amounts of rutin, myricetin, quercetin, and kaempferol. Janbaz, Saeed, and Gilani (2004) suggested that the antioxidant and antifibrotic effect of a gooseberry may be due to the presence of a high amount of quercetin which has strong antioxidant activity and anti-inflammatory properties (Boots et al., 2008). In addition to quercetin, gooseberry also contains kaempferol 3-Orutinoside that considered as antioxidant due to its ability to scavenge free radicals and ROS (Tatsimo,

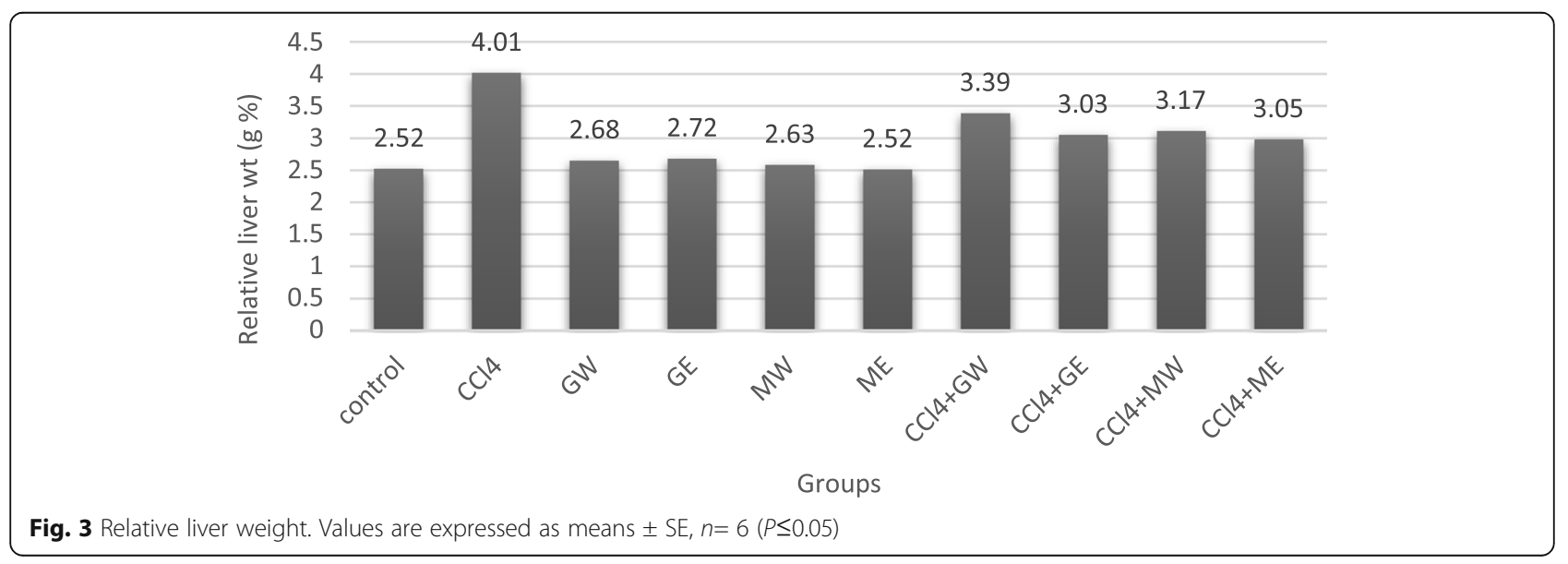


Table 2 Biomarkers of liver lesions

\begin{tabular}{|c|c|c|c|c|c|}
\hline Groups & ALT (U/I) & AST (U/I) & ALP (U/I) & AFP $(\mathrm{ng} / \mathrm{ml})$ & Hydroxy proline ( $\mathrm{mg} / \mathrm{g}$ tissue) \\
\hline Control & $38.41 \pm 2.25^{\mathrm{a}, c}$ & $103.20 \pm 2.03^{a}$ & $119.08 \pm 0.60^{\mathrm{a}}$ & $0.566 \pm 0.01^{\mathrm{a}}$ & $28.02 \pm 0.54^{a}$ \\
\hline $\mathrm{CCl}_{4}$ & $224.56 \pm 2.59^{b}$ & $333.34 \pm 2.11^{b}$ & $201.83 \pm 2.08^{b}$ & $4.350 \pm 0.40^{b}$ & $59.33 \pm 0.94^{b}$ \\
\hline GW & $37.04 \pm 0.90^{\mathrm{a}, \mathrm{c}}$ & $104.25 \pm 0.44^{\mathrm{a}}$ & $117.39 \pm 0.70^{\mathrm{a}, c}$ & $0.582 \pm 0.02^{\mathrm{a}}$ & $22.66 \pm 0.28^{c, d}$ \\
\hline GE & $39.71 \pm 0.84^{c}$ & $106.70 \pm 2.37^{\mathrm{a}}$ & $117.48 \pm 1.11^{a, c}$ & $0.661 \pm 0.04^{\mathrm{a}}$ & $21.48 \pm 0.33^{\mathrm{d}}$ \\
\hline MW & $34.71 \pm 0.36^{\mathrm{a}}$ & $105.83 \pm 1.42^{\mathrm{a}}$ & $118.33 \pm 0.57^{\mathrm{a}, \mathrm{c}}$ & $0.653 \pm 0.03^{\mathrm{a}}$ & $23.98 \pm 1.23^{c}$ \\
\hline ME & $35.59 \pm 0.14^{a, c}$ & $104.58 \pm 1.40^{\mathrm{a}}$ & $115.20 \pm 1.66^{c}$ & $0.650 \pm 0.01^{\mathrm{a}}$ & $22.40 \pm 0.93^{c, d}$ \\
\hline $\mathrm{CCl}_{4}+\mathrm{GW}$ & $66.38 \pm 1.64^{d}$ & $128.75 \pm 2.13^{d}$ & $139.01 \pm 0.46^{d}$ & $1.75 \pm 0.06^{c}$ & $37.01 \pm 0.60^{e}$ \\
\hline $\mathrm{CCl}_{4}+\mathrm{GE}$ & $88.16 \pm 1.30^{\mathrm{e}}$ & $134.66 \pm 1.56^{\mathrm{e}}$ & $142.00 \pm 0.78^{d}$ & $1.65 \pm 0.04^{c}$ & $33.13 \pm 1.46^{f}$ \\
\hline $\mathrm{CCl}_{4}+\mathrm{MW}$ & $89.02 \pm 2.10^{e}$ & $134.98 \pm 1.81^{\mathrm{e}}$ & $138.78 \pm 0.25^{d}$ & $1.95 \pm 0.05^{d}$ & $37.04 \pm 0.57^{e}$ \\
\hline $\mathrm{CCl}_{4}+\mathrm{ME}$ & $64.62 \pm 1.69^{d}$ & $120.60 \pm 0.68^{f}$ & $138.10 \pm 1.70^{d}$ & $2.01 \pm 0.04^{d}$ & $37.11 \pm 1.04^{\mathrm{e}}$ \\
\hline
\end{tabular}

Values are expressed as means $\pm \mathrm{SE}, n=6$. There was no significant difference between means have the same letter in the same column $(P \leq 0.05)$

Tamokou, Havyarimana, et al., 2012). Moreover, the study of Ahmed (2014) on the ethanolic extract of Physalis peruviana L. detected the presence of phytosterols and saponin also which have antioxidant activity. Furthermore, Physalis peruviana L. extracts contain many withanolide glycosides which are natural steroidal lactones produced by plants in the Solanaceae and often have many health benefits such as anti-inflammatory activity (Lan, Chang, Pan, et al., 2009). It has been also reported that the water extract of Physalis peruviana contains phytochemicals, flavonoids, saponins, and phenols (Arun \& Asha, 2007).

Bao et al. (2016) showed that black mulberry extract contains large amounts of flavonoids, phenolic compounds, and anthocyanins, which exhibit many bioactive features including antioxidant, anti-inflammatory, antiobesity, anti-atherogenesis, and anticancer properties. It has been reported that black mulberry is a plant rich in fatty acids, such as linoleic, stearic, and oleic acids and other molecules that possess antioxidant, antiinflammatory, and analgesic effects (Feng et al., 2015).
The results of a qualitative investigation performed by Mallhi et al. (2014) revealed the presence of luteolin, quercetin, and isorhamnetin in aqueous methanolic extract of M. nigra. Luteolin (Domitrović, Jakovac, Milin, \& Radošević-Stašić, 2009), isorhamnetin (Kim, Kim, Choi, \& Lee, 2012), and quercetin (Janbaz et al., 2004) all are known for their antioxidant and hepatoprotective potential. The results presented by Chang et al. (2011) illustrate that ethanolic extract of mulberry exhibited radical scavenging and reducing activity due to its high content of phenolic compounds such as maclurin, rutin, isoquercitrin, and resveratrol.

Carbon tetrachloride is a common environmental pollutant that causes hepatocyte injuries and altered membrane integrity, and as a result, enzymes in hepatocytes leak out ( $\mathrm{Hu}$ et al., 2000). $\mathrm{CCl}_{4}$ is metabolized by the cytochrome $\mathrm{P} 450$ system to highly reactive trichloromethyl radical $\left(\mathrm{CCl}_{3}{ }^{\circ}\right)$ and trichloromethyl peroxyl radical $\left(\mathrm{CCl}_{3} \mathrm{OO}{ }^{*}\right)$, which cause liver cell destruction. These free radicals initiate autoxidation of cytoplasmic membrane fatty acids and cause accumulation of lipid-

Table 3 Oxidant/antioxidant status

\begin{tabular}{lllll}
\hline Groups & GSH (mmol/g tissue) & GPx (U/g tissue) & MDA (nmol/g tissue) & NO ( $\mathbf{\mu m o l} / \mathbf{g}$ tissue) \\
\hline Control & $50.86 \pm 2.35^{\mathrm{a}}$ & $119.30 \pm 0.66^{\mathrm{a}}$ & $49.90 \pm 0.40^{\mathrm{a}}$ & $3.68 \pm 0.09^{\mathrm{a}}$ \\
$\mathrm{CCl}_{4}$ & $21.80 \pm 0.35^{\mathrm{b}}$ & $69.30 \pm 0.47^{\mathrm{b}}$ & $96.45 \pm 2.87^{\mathrm{b}}$ & $7.40 \pm 0.11^{\mathrm{b}}$ \\
$\mathrm{GW}$ & $56.35 \pm 1.49^{\mathrm{c}}$ & $122.86 \pm 1.11^{\mathrm{a}, \mathrm{c}}$ & $45.16 \pm 0.80^{\mathrm{c}}$ & $2.53 \pm 0.67^{\mathrm{c}}$ \\
$\mathrm{GE}$ & $62.27 \pm 1.41^{\mathrm{d}}$ & $124.58 \pm 1.79^{\mathrm{c}, \mathrm{d}}$ & $40.39 \pm 0.21^{\mathrm{d}}$ & $2.23 \pm 0.07^{\mathrm{c}}$ \\
$\mathrm{MW}$ & $57.80 \pm 1.32^{\mathrm{c}}$ & $122.13 \pm 1.94^{\mathrm{a}, \mathrm{d}}$ & $43.75 \pm 0.84^{\mathrm{c}, \mathrm{d}}$ & $2.77 \pm 0.18^{\mathrm{c}}$ \\
$\mathrm{ME}$ & $56.43 \pm 1.42^{\mathrm{c}}$ & $123.54 \pm 1.15^{\mathrm{a}, \mathrm{d}}$ & $43.51 \pm 1.23^{\mathrm{c}, \mathrm{d}}$ & $2.70 \pm 0.04^{\mathrm{c}}$ \\
$\mathrm{CCl}{ }_{4}+\mathrm{GW}$ & $40.66 \pm 0.42^{\mathrm{e}}$ & $98.66 \pm 1.18^{\mathrm{e}}$ & $63.53 \pm 0.44^{\mathrm{e}}$ & $4.47 \pm 0.23^{\mathrm{d}}$ \\
$\mathrm{CCl}_{4}+\mathrm{GE}$ & $35.26 \pm 1.13^{\mathrm{f}}$ & $98.61 \pm 3.18^{\mathrm{e}}$ & $55.67 \pm 2.75^{\mathrm{f}}$ & $4.10 \pm 0.09^{\mathrm{a}, d}$ \\
$\mathrm{CCl}_{4}+\mathrm{MW}$ & $34.02 \pm 1.18^{\mathrm{f}}$ & $87.92 \pm 0.77^{\mathrm{f}}$ & $74.82 \pm 0.96^{\mathrm{g}}$ & $5.40 \pm 0.48^{\mathrm{e}}$ \\
$\mathrm{CCl}_{4}+\mathrm{ME}$ & $36.63 \pm 1.51^{\mathrm{f}}$ & $96.21 \pm 2.99^{\mathrm{e}}$ & $68.58 \pm 1.07^{\mathrm{h}}$ & $4.35 \pm 0.30^{\mathrm{d}}$
\end{tabular}

Values are expressed as means $\pm \mathrm{SE}, n=6$, There was no significant difference between means have the same letter in the same column $(P \leq 0.05)$ 
Table 4 Plasma cytokines levels

\begin{tabular}{|c|c|c|c|c|}
\hline Groups & IFN $\gamma(\mathrm{pg} / \mathrm{ml})$ & TNF-a (pg/ml) & NF-KB (ng/ml) & Adiponectin $(\mathrm{pg} / \mathrm{ml})$ \\
\hline Control & $44.74 \pm 1.05^{\mathrm{a}}$ & $32.21 \pm 0.96^{\mathrm{a}}$ & $94.71 \pm 1.17^{\mathrm{a}}$ & $9.55 \pm 0.17^{\mathrm{a}}$ \\
\hline $\mathrm{CCl}_{4}$ & $87.72 \pm 0.62^{b}$ & $75.90 \pm 0.64^{b}$ & $138.48 \pm 2.73^{b}$ & $4.01 \pm 0.20^{b}$ \\
\hline GW & $36.21 \pm 0.38^{c}$ & $25.76 \pm 0.60^{c}$ & $83.45 \pm 0.64^{c}$ & $8.16 \pm 0.15^{c}$ \\
\hline GE & $34.72 \pm 0.70^{c}$ & $21.90 \pm 0.36^{d}$ & $74.08 \pm 1.60^{d}$ & $7.91 \pm 0.10^{c}$ \\
\hline MW & $35.71 \pm 1.14^{c}$ & $25.66 \pm 0.71^{c}$ & $86.81 \pm 0.89^{c}$ & $8.30 \pm 0.29^{c}$ \\
\hline ME & $34.04 \pm 1.00^{c}$ & $26.55 \pm 0.38^{c}$ & $83.52 \pm 0.42^{c}$ & $8.00 \pm 0.18^{c}$ \\
\hline $\mathrm{CCl}_{4}+\mathrm{GW}$ & $52.30 \pm 0.78^{d}$ & $55.48 \pm 1.22^{\mathrm{e}}$ & $105.21 \pm 3.04^{e, f}$ & $6.15 \pm 0.22^{\mathrm{d}, \mathrm{e}}$ \\
\hline $\mathrm{CCl}_{4}+\mathrm{GE}$ & $52.95 \pm 1.50^{d}$ & $49.24 \pm 0.22^{f}$ & $106.99 \pm 0.44^{e}$ & $7.06 \pm 0.27^{f, g}$ \\
\hline $\mathrm{CCl}_{4}+\mathrm{MW}$ & $57.00 \pm 2.21^{e}$ & $55.51 \pm 1.29^{e}$ & $110.68 \pm 3.92^{e}$ & $6.55 \pm 0.26^{e, g}$ \\
\hline $\mathrm{CCl}_{4}+\mathrm{ME}$ & $53.15 \pm 2.77^{d}$ & $54.39 \pm 1.26^{\mathrm{e}}$ & $99.83 \pm 2.66^{\mathrm{a}, \mathrm{f}}$ & $6.81 \pm 0.27^{9}$ \\
\hline
\end{tabular}

Values are expressed as means $\pm \mathrm{SE}, n=6$, There was no significant difference between means have the same letter in the same column ( $P \leq 0.05)$

derived oxidation products, thiobarbituric acid reactive substances (TBARS), leading to cell membrane damage and eventually liver diseases (Jaeschke, 2011). The body's own antioxidants system (endogenous antioxidant) or supplemented antioxidant from the diet (exogenous antioxidant) can counteract oxidative stress induced by $\mathrm{CCl}_{4}$ by neutralizing the excess free radicals and protect cells against their toxic effects (Wahid, Hamed, Eltahir, \& Abouzied, 2016).

According to biochemical analysis and histopathological examination of liver tissue, administration of $\mathrm{CCl}_{4}$ at a dose of $1 \mathrm{ml} / \mathrm{kg}$ body weight 3 times a week successfully induced hepatoxicity. In this study, all groups showed no mortality, which was in accordance with Muriel, Moreno, Hernández Mdel, Chávez, and Alcantar (2015) who reported that after 1 month of chronic $\mathrm{CCl}_{4}$ intoxication $100 \%$ of rats survived. However, mortality appeared only after 2 months of intoxication $(5.55 \%)$, increased to $26.6 \%$ by 3 months, and reached $55.5 \%$ at month 4 of chronic intoxication with $\mathrm{CCl}_{4}$.

Hepatosomatic index (relative liver weight to body weight) is fundamental to liver injury diagnosis (Saxena, Rathor, Mahour, Saxena, \& Bajaj, 2010). The results presented in Figs. 1, 2, and 3 show significant lower body weight, higher liver weight, and relative liver weight in $\mathrm{CCl}_{4}$-treated rats when compared to control. Dutta et al. (2018) showed that the increase in liver weight may be probably due to the formation of reactive oxygen species (ROS) which led to hepatic damage and liver inflammation. On the other hand, administration of aqueous and ethanolic extracts of gooseberry and black mulberry appeared to enhance the liver-body weight ratio (HSI).

In the current work, administration of $\mathrm{CCl}_{4}$ markedly increased the plasma level of liver enzymes (ALT, AST, and ALP), which are indices of liver cell damage and leakage of enzymes from cells. Essawy, Abdel-Moneim, Khayyat, and Elzergy (2012) reported that the rise in
ALT activity is almost always due to hepatocellular damage and is usually accompanied by a rise in AST and ALP. Alpha-fetoprotein (AFP) is an $\alpha 1$-globulin secreted by fetal hepatocytes and in a small amount by other cells of the fetal gastrointestinal tract (El Raziky et al., 2013). The present data showed increased AFP in rats treated with $\mathrm{CCl}_{4}$; this increase may be due to the hepatotoxic effect associated with $\mathrm{CCl}_{4}$. Our results showed amelioration in plasma levels of ALT, AST, ALP, and AFP in rats treated with the tested extracts (Table 2) which is a clear indication of the improvement in the functional status of the liver and protection of cellular architecture.

Liver tissue fibrosis of the $\mathrm{CCl}_{4}$ group is evident from the increased hepatic level of hydroxyproline and histopathological examination of liver tissue. Hydroxyproline is an abundant amino acid present in collagen; the presence of hydroxyproline in the extracellular matrix produced by activated hepatic stellate cells preserves the integrity and function of liver cells. Its level in liver tissues could correctly indicate the rates and progression of liver fibrogenesis (Gabr, Alghadir, Sherif, \& Ghfar, 2016). Treatment with the tested extracts either alone or along with $\mathrm{CCl}_{4}$ markedly reduced the hepatic collagen deposition marker, hydroxyproline, indicating their protective effects against collagen deposition and liver fibrosis (Table 2).

In this work, $\mathrm{CCl}_{4}$ causes noticeable toxicity by enhancing liver lipid peroxidation (LPO), as indicated by the elevated concentration of hepatic MDA, and increased production of reactive nitrogen species (RNS) such as NO. Nitric oxide is known to react with superoxide anion, forming highly reactive peroxynitrite (ONOO--) radical, which can cause cytotoxicity and DNA damage through LPO (Tipoe et al., 2010). It has been suggested that lipid peroxidation may be a link between tissue injury and liver fibrosis by modulating collagen gene expression (Parola \& Robino, 2001). The liver intoxication induced by $\mathrm{CCl}_{4}$ also causes significant depletion of the 


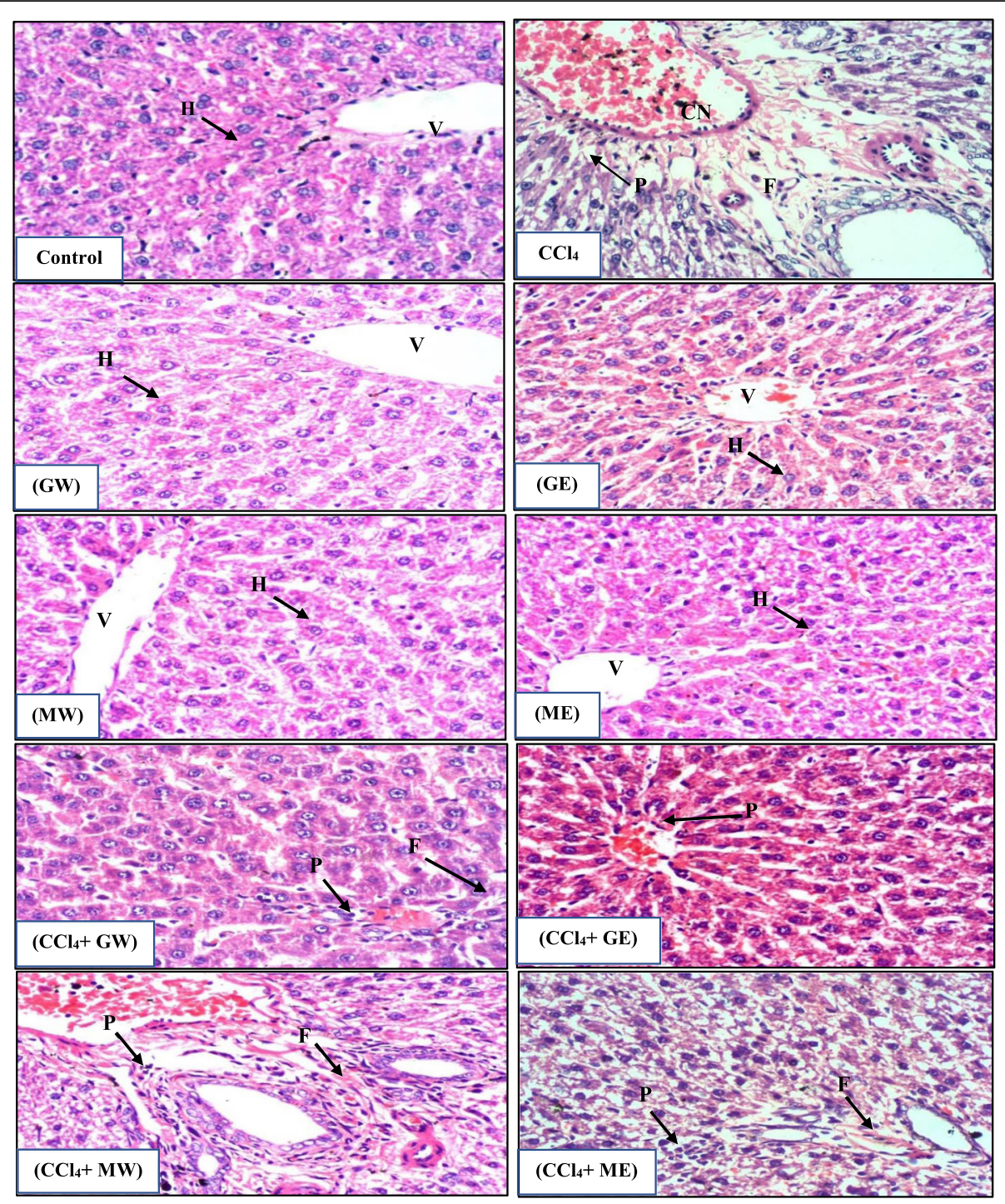

Fig. 4 Photomicrograph of liver stained with H\&E showing the following: Normal architecture with the central vein ( $V$ ) surrounded by hepatocytes $(\mathrm{H})$ (control group). Destruction of hepatic architecture with apparent portal fibrosis (F), periportal aggregations of inflammatory cells $(\mathrm{P})$, and marked congestion (Cn) of blood vessels ( $\mathrm{CCl}_{4}$ group). Normal architecture of hepatocyte (GW, GE, MW, and ME groups), respectively. Few lymphocyte infiltrations and little fibrosis (CCl $4+G W$ group). Few lymphocyte infiltrations and no fibrosis $\left(\mathrm{CCl}_{4}+\mathrm{GE}\right.$ group). Some fibrosis (F) and lymphatic aggregation(P) $\left(\mathrm{CCl}_{4}+\mathrm{MW}\right.$ group). Few lymphocyte infiltrations $(\mathrm{P})$ and some fibrosis $(\mathrm{F})\left(\mathrm{CCl}_{4}+\mathrm{ME}\right.$ group) $(\mathrm{H} \& \mathrm{E} \times 400)$

Table 5 Summary of the histopathological findings

\begin{tabular}{llll}
\hline Groups & Fibrosis & Inflammatory cells infiltration & Congestion of blood vessels \\
\hline Control & Absent & Absent & Absent \\
$\mathbf{C C l}_{4}$ & Apparent portal fibrosis & Periportal aggregations of inflammatory cells & Present \\
$\mathbf{G W}$ & Absent & Absent & Absent \\
$\mathbf{G E}$ & Absent & Absent & Absent \\
$\mathbf{M W}$ & Absent & Absent & Absent \\
$\mathbf{M E}$ & Absent & Absent & Absent \\
$\mathrm{CCl}_{4}+\mathrm{GW}$ & Little periportal fibrosis & Few lymphocyte infiltrations & Absent \\
$\mathrm{CCl}_{4}+\mathrm{GE}$ & Absent & Few lymphocyte infiltrations & Absent \\
$\mathrm{CCl}_{4}+\mathbf{M W}$ & Little periportal fibrosis & Few lymphocyte infiltrations & Absent \\
$\mathbf{C C l}_{4}+\mathrm{ME}$ & Little periportal fibrosis & Few lymphocyte infiltrations & Absent \\
\hline
\end{tabular}


antioxidants $\mathrm{GSH}$ and $\mathrm{GP}_{\mathrm{X}}$ in the liver tissue which was in accordance with EL-Dakhly et al. (2020). On the other hand, our results prove the protective effects of the tested extracts against $\mathrm{CCl}_{4}$-induced oxidative stress which is illustrated by amelioration of the depleted levels of GSH and GPx and decreased the levels of hepatic MDA and $\mathrm{NO}$ in the $\mathrm{CCl}_{4}$-treated rats (Table 3).

In the current study, $\mathrm{CCl}_{4}$-treated rats showed inflammation and hence an overexpression of inflammatory biomarkers (IFN $\gamma$, TNF- $\alpha$, and NF-Kb) in plasma. It was suggested that IFN- $\gamma$ increases liver injury by stimulating hepatic inflammation and aggravating liver damage; this is accompanied by an increase in hepatic fibrogenesis (Knight, Lim, Yeoh, \& Olynyk, 2007). The TNF- $\alpha$ activity also is increased in many forms of experimental liver injury (Riddle et al., 2014). Nuclear Factor $\mathrm{kB}$ is a transcription factor that regulates the expression of genes involved in the inflammation process (Sun et al., 2007). These pro-inflammatory cytokines are also involved in the activation of HSCs which have been identified as major collagen-producing cells in the injured liver, playing a role in the production of fibrous tissue and extracellular matrix components (Peng et al., 2009). Hamza et al. (2020) found that repeated administration of $\mathrm{CCl}_{4}$ caused significant fibrosis of liver cells and release of liver injury markers with a range of inflammatory reactions and oxidative stress.

Our results also showed that the level of plasma adiponectin (adipocytokine) in the $\mathrm{CCl}_{4}$ intoxicated group was lower than normal; this agreed with the previous studies of Abdel-Moneim, Al-Kahtani, ElKersh, and Al-Omair (2015) and $\mathrm{Li}$ et al. (2009). It was indicated that adiponectin level is downregulated in several liver pathological processes, as steatosis, inflammation, and fibrosis (Buechler, Wanninger, \& Neumeier, 2011). Adiponectin has many anti-inflammatory activities as it suppresses TNF- $\alpha$. The anti-inflammatory effects of adiponectin are also exerted by induction of the anti-inflammatory cytokines interleukin-10 (IL-10) or IL-1 receptor antagonist and upregulation of heme-oxygenase-1 (Moschen, Wieser, \& Tilg, 2012). Treatment with the natural tested extracts reversed the decrease of adiponectin level induced by $\mathrm{CCl}_{4}$; moreover, lower levels of IFN- $\gamma$, TNF- $\alpha$, and NF-KB are indicative of improved anti-inflammatory effects and reduction of hepatic inflammation and fibrogenesis (Table 4). We hypothesize that gooseberry and black mulberry extracts might protect the liver from $\mathrm{CCl}_{4}$-caused injury and fibrogenesis by attenuating oxidative stress and suppressing inflammation.

The histological observations of liver tissues support the results obtained from the biochemical assays. Administration of $\mathrm{CCl}_{4}$ caused degenerative changes in hepatocytes, including the destruction of hepatic architecture, marked portal fibrosis, activation of hepatic stellate cells, periportal aggregations of inflammatory cells, and congestion of blood vessels; this goes in accordance with the previous studies of Wahid et al. (2016) and Sansoè et al. (2016).On the other hand, administration of our tested extracts along with $\mathrm{CCl}_{4}$ was able to show an improvement in the liver tissue comparing to the $\mathrm{CCl}_{4}$ group (Fig. 4).

The hepatoprotective effects of gooseberry and black mulberry extracts are also supported by the previous studies of Arun and Asha (2007), Al-Olayan et al. (2014), and Deniz, Laloglu, Koc, Nadaroglu, and Geyikoglu (2018). Results from Abd El-Rahman, Abd-Elhak, and Zaki (2020) study indicated the efficacy of cape gooseberry and black mulberry as a promising antihepatotoxic agent because they have high antioxidant activity.

\section{Conclusion}

Our study concluded that the aqueous and ethanolic extracts of gooseberry and black mulberry significantly protect the liver from injury induced by $\mathrm{CCl}_{4}$ in rats by reducing the biomarkers of liver lesions (ALT, AST, ALP, AFP, and hydroxyproline). Besides, the tested extracts attenuate oxidative stress by increasing the content of hepatic GSH and GPx, leading to a reduction in the levels of MDA and NO. The tested extracts also suppress inflammation by reducing the levels of plasma proinflammatory cytokines INF- $\gamma$, TNF- $\alpha$, and NF-KB and elevating the level of plasma adiponectin. Furthermore, the microscopic examination showed improving histological architecture of the liver and reduction of fibrosis. The hepatoprotective effect of the gooseberry and blackmulberry extracts is due to their high content of flavonoids, polyphenols, and their antioxidant activity. Ethanolic extract of gooseberry (GE) showed the most significant hepatoprotective activity followed by ethanolic extract of mulberry (ME).

\section{Abbreviations \\ $\mathrm{CCl}_{4}$ : Carbon tetrachloride; GW: Water extract of gooseberry; GE: Ethanolic extract of gooseberry; MW: Water extract of black mulberry; ME: Ethanolic extract of black mulberry; ALT: Alanine transaminase; AST: Aspartate transaminase; ALP: Alkaline phosphatase; AFP: Alpha-fetoprotein; GSH: Reduced glutathione; GPx: Glutathione peroxidase; \\ MDA: Malondialdehyde; NO: Nitric oxide; IFN Y: Interferon-gamma; TNF- a: Tumor necrosis factor-alpha; NF-KB: Nuclear Factor Kb; GAEs: Gallic acid equivalents; DPPH: a,a-Diphenyl- $\beta$ - picryl- hydrazyl; QE: Quercetin equivalent; OD: Optical density; SE: Standard error; HSI: Hepatosomic index; \\ H\&E: Hematoxylin and eosin; LPO: Lipid peroxidation; b.wt: Body weight; LSD: Least significant difference; ROS: Reactive oxygen spices; RNS: Reactive nitrogen spices; ELISA: Enzyme-linked immunosorbent assay; \\ TBARS: Thiobarbituric acid reactive substances; pg: Picograms; ng: Nanogram}

\section{Acknowledgements}

Not applicable

Authors' contributions

ES contributed to the design and conception of the study, analysis, and interpretation of data and drafted and revised the manuscript. MM also 
contributed to the design and conception of the study and preparation of materials required for the study. The two authors read and approved the manuscript.

\section{Funding}

This study was self-funded by the authors.

\section{Availability of data and materials}

The datasets analyzed during the present study are available from the corresponding author on reasonable request.

\section{Declarations}

\section{Ethics approval and consent to participate}

The protocol of this study was approved by the research ethical approval committee of the Medical Research Center, Ain Shams University, Cairo, Egypt. The Guidelines and Principles of laboratory animal care ( $\mathrm{NIH}$ publication No. 85-23, revised 1985) were followed, as well as specific national laws where applicable. The living conditions of animals were appropriate for their species and contribute to their health and comfort (the housing, feeding, and care of all). The authors ensured that all individuals who deal with animals were under their supervision and received explicit instruction in experimental methods and in the care, maintenance, and handling of the rats. The authors were refining the experimental procedures themselves. They were carefully assessing the method of administration, the effects of the substance on the animal, and the amount of handling and restraint required. All rats were sacrificed using euthanasia to prevent the animals from feeling pain

\section{Consent for publication}

Not applicable

\section{Competing interests}

Authors have declared that no competing interests exist.

\section{Author details}

'Department of Biochemistry and Nutrition, Faculty of Women for Arts, Science and Education, Ain Shams University, Cairo, Egypt. ${ }^{2}$ Department of Surgical Pathology, National Cancer Institute, Cairo University, Cairo, Egypt.

\section{Received: 18 May 2020 Accepted: 3 May 2021}

\section{Published online: 30 May 2021}

\section{References}

Abd El-Rahman, H. S. M., Abd-Elhak, N. A., \& Zaki, N. L. (2020). Hepatoprotective effects of mulberries and cape gooseberry on thioacetamide induced liver injury in rats. American Journal of Food and Nutrition, 8(4), 101-112.

Abdel-Moneim, A. M., Al-Kahtani, M. A., ElKersh, M. A., \& Al-Omair, M. A. (2015). Free radical scavenging, anti-inflammatory/anti-fibrotic and hepatoprotective actions of taurine and silymarin against $\mathrm{CCl} 4$ induced rat liver damage. PLOS One, 10(12), 1-16.

Acosta, A. A. (1983). Direct immunoenzymatic determination of AFP in serum or plasma. Journal of Clinical Immunoassay, 6, 41 .

Ahmed, L. A. (2014). Renoprotective effect of Egyptian cape gooseberry fruit (Physalis peruviana L.) against acute renal injury in rats. The Scientific World Journal, 2014.

Ahmed, T. M., Eldemardash, E. S., \& Ali, S. A. (2019). Antioxidant and hepatoprotective effects of ethanolic extracts of Faidherbia albida fruits and stem bark against carbon tetrachloride induced liver damage in rats. SUST Journal of Agricultural and Veterinary Sciences., 20(1), 1-8.

Al-Olayan, E. M., El-Khadragy, M. F., Aref, A. M., Othman, M. S., Kassab, R. B., \& Abdel Moneim, A. E. (2014). The potential protective effect of Physalis peruviana L. against carbon tetrachloride-induced hepatotoxicity in rats is mediated by suppression of oxidative stress and downregulation of MMP-9 expression. Oxidative Medicine and Cellular Longevity, 2014, 381413.

Arun, M., \& Asha, V. V. (2007). Preliminary studies on antihepatotoxic effect of Physalis peruviana Linn. (Solanaceae) against carbon tetrachloride induced acute liver injury in rats. Journal of Ethnopharmacology, 111(1), 110-114. https://doi.org/10.1016/j.jep.2006.10.038.

Ausseil, F., Samson, A., Aussaques, Y., Vandenberghe, I., Creancier, L., Pouny, I., .. Bailly, C. (2007). High-throughput bioluminescence screening of ubiquitin- proteasome pathway inhibitors from chemical and natural sources. Journal of Biomolecular Screening, 12(1), 106-116. https://doi.org/10.1177/10870571062 96494

Bancroft, J. D., Stevens, A., \& Turner, D. R. (1996). Theory and practice of histological techniques, (4th ed., ). Churchill.

Bao, T., Xu, Y., Gowd, V., Zhao, J., Xie, J., Liang, W., \& Chen, W. (2016). Systematic study on phytochemicals and antioxidant activity of some new and common mulberry cultivars in China. Journal of Functional Foods, 25, 537547. https://doi.org/10.1016/j.jf.2016.07.001.

Belfield, \& Goldberg (1971). Normal ranges and diagnostic value of serum 5 'nucleotidase and alkaline phosphatase activities in infancy. Archives of Disease in Childhood, 46(250), 842-846. https://doi.org/10.1136/adc.46.250.842.

Beutler, E., Duron, O., \& Kelly, M. B. (1963). Improved method for the determination of blood glutathione. The Journal of Laboratory and Clinical Medicine, 61, 882-888.

Boots, A. W., Wilms, L. C., Swennen, E. L. R., Kleinjans, J. C. S., Bast, A., \& Haenen, G. R. M. M. (2008). In vitro and ex vivo anti-inflammatory activity of quercetin in healthy volunteers. Nutrition, 24(7-8), 703-710.

Brand-Williams, W., Cuvelier, M. E., \& Berset, C. (1995). Use of a free radical method to evaluate antioxidant activity. LWT - Food Science and Technology, 28(1), 25-30. https://doi.org/10.1016/S0023-6438(95)80008-5.

Buechler, C., Wanninger, J., \& Neumeier, M. (2011). Adiponectin, a key adipokine in obesity related liver diseases. World Journal of Gastroenterology, 17(23), 2801-2811. https://doi.org/10.3748/wjg.v17.i23.2801.

Chang, L., Juang, L., Wang, B., Wang, M., Tai, H., Hung, W., ... Huang, M. (2011). Antioxidant and antityrosinase activity of mulberry (Morus alba L.) twigs and root bark. Food and Chemical Toxicology, 49(4), 785-790. https://doi.org/10.1 016/j.fct.2010.11.045.

Cullen, J. (2005). Mechanistic classification of liver injury. Toxicologic Pathology, 33(1), 6-8. https://doi.org/10.1080/01926230590522428.

Deng, G., Wang, J., Zhang, Q., He, H., Wu, F., Feng, T., ... Hattori, M. (2012). Hepatoprotective effects of phloridzin on hepatic fibrosis induced by carbon tetrachloride against oxidative stress-triggered damage and fibrosis in rats. Biological \& Pharmaceutical Bulletin, 35(7), 1118-1125. https://doi.org/10.1248/ bpb.b12-00057.

Deniz, G. Y., Laloglu, E., Koc, K., Nadaroglu, H., \& Geyikoglu, F. (2018). The effect of black mulberry (Morus nigra) extract on carbon tetrachloride-induced liver damage. Archives of Biological Sciences, 70(2), 371-378. https://doi.org/10.22 98/ABS171009055D.

Domitrović, R., Jakovac, H., Milin, Č., \& Radošević-Stašić, B. (2009). Dose and timedependent effects of luteolin on carbon tetrachloride-induced hepatotoxicity in mice. Experimental and Toxicologic Pathology, 61(6), 581-589. https://doi. org/10.1016/j.etp.2008.12.005.

Dutta, S., Chakraborty, A. K., Dey, P., Kar, P., Guha, P., Sen, S., et al. (2018). Amelioration of $\mathrm{CCl} 4$ induced liver injury in Swiss albino mice by antioxidant rich leaf extract of Croton bonplandianus Baill. PLoS One, 13(4), 1-30.

El Raziky, M., Attia, D., El Akel, W., Shaker, O., Khatab, H., Abdo, S., ... Esmat, G. (2013). Hepatic fibrosis and serum alpha-fetoprotein (AFP) as predictors of response to HCV treatment and factors associated with serum AFP normalization after treatment. Arab Journal of Gastroenterology, 14, 94-98.

EL-Dakhly, S. M., Salama, A. A. A., Hassanin, S. O. M., Yassen, N. Z., Hamza, A. A., \& Amin, A. (2020). Aescin and diosmin each alone or in low dose- combination ameliorate liver damage induced by carbon tetrachloride in rats. BMC Research Notes, 13, 259.

Essawy, A. E., Abdel-Moneim, A. M., Khayyat, L. I., \& Elzergy, A. A. (2012). Nigella sativa seeds protect against hepatotoxicity and dyslipidemia induced by carbon tetrachloride in mice. Journal of Applied Pharmaceutical Science., 2(10), 021-025.

Feng, R. Z., Wang, Q., Tong, W. Z., Xiong, J., Wei, Q., Zhou, W. H., et al. (2015). Extraction and antioxidant activity of flavonoids of Morus nigra. International Journal of Clinical and Experimental Medicine, 8, 22328-22336.

Gabr, S. A., Alghadir, A. H., Sherif, Y. E., \& Ghfar, A. A. (2016). Hydroxyproline as a biomarker in liver disease. In V. Preedy (Ed.), Biomarkers in liver disease. Biomarkers in disease: Methods, discoveries, and applications. Springer.

Hamza, A. A., Lashin, F. M., Gamel, M., Hassanin, S. O., Abdalla, Y., \& Amin, A. (2020). Hawthorn herbal preparation from Crataegus oxyacantha attenuates in vivo carbon tetrachloride -induced hepatic fibrosis via modulating oxidative stress and inflammation. Antioxidants., 9(12), 1173. https://doi.org/1 0.3390/antiox9121173.

Hu, Y. Y., Liu, C. H., Wang, R. P., Liu, C., Liu, P., \& Zhu, D. Y. (2000). Protective actions of salvianolic acid a on hepatocyte injured by peroxidation in vitro. 
World Journal of Gastroenterology, 6(3), 402-404. https://doi.org/10.3748/wjg. v6.i3.402.

Huang, H. P., Shih, Y. W., Chang, Y. C., Hung, C. N., \& Wang, C. J. (2008). Chemo inhibitory effect of mulberry anthocyanins on melanoma metastasis involved in the Ras/ PI3K pathway. Journal of Agricultural and Food Chemistry, 56(19), 9286-9293. https://doi.org/10.1021/jf8013102.

Jaeschke, H. (2011). Reactive oxygen and mechanisms of inflammatory liver injury: Present concepts. Journal of Gastroenterology and Hepatology, 26(1), 173-179. https://doi.org/10.1111/j.1440-1746.2010.06592.x.

Janbaz, K. H., Saeed, S. A., \& Gilani, A. H. (2004). Studies on the protective effects of caffeic acid and quercetin on chemical-induced hepatotoxicity in rodents. Phytomedicine, 11(5), 424-430. https://doi.org/10.1016/j.phymed.2003.05.002.

Kähkönen, M. P., Hopia, A. I., Vuorela, H. J., Rauha, J., Pihlaja, K., Kujala, T. S., et al. (1999). Antioxidant activity of plant extracts containing phenolic compounds. Journal of Agricultural and Food Chemistry, 47(10), 3954-3962. https://doi. org/10.1021/jf9901461.

Kang, T. H., Hur, J. Y., Kim, H. B., Ryu, J. H., Kim, S., \& Y. (2006). Neuroprotective effects of the cyanidin-3-O-beta-D-glucopyranoside isolated from mulberry fruit against cerebral ischemia. Neuroscience Letters, 391(3), 122-126. https:// doi.org/10.1016/j.neulet.2005.08.053.

Kim, D. W., Kim, K. M., Choi, J. S., \& Lee, S. M. (2012). Isorhamnetin-3-Ogalactoside protects against CCl4-induced hepatic injury in mice. Biomolecules \& Therapeutics, 20(4), 406-412. https://doi.org/10.4062/biomolther.2012.20.4.406

Knight, B., Lim, R., Yeoh, G. C., \& Olynyk, J. K. (2007). Interferon-y exacerbates liver damage, the hepatic progenitor cell response, and fibrosis in a mouse model of chronic liver injury. Journal of Hepatology, 47(6), 826-833. https://doi.org/1 0.1016/.j.jhep.2007.06.022.

Lan, Y. H., Chang, F. R., Pan, M. J., et al. (2009). New cytotoxic withanolides from Physalis peruviana. Food Chemistry, 116(2), 462-469.

Lee, S. W., Pan, M. H., Chen, C. M., \& Chen, Z. T. (2008). Withangulatin I, a new cytotoxic withanolide from Physalis angulata. Chemical \& Pharmaceutical Bulletin (Tokyo), 56(2), 234-236. https://doi.org/10.1248/cpb.56.234.

Levesque, R. (2007). SPSS programming and data management: A guide for SPSS and SAS user, (3rd ed., ).

Li, H. S., Feng, Q., Xu, L. L., Chen, S. D., Li, X. M., \& Hu, Y. Y. (2009). Effects of Qushi Huayu decoction in prevention and treatment of fatty liver in rats based on adiponectin-free fatty acid pathway. Journal Chinese of Integrative Medicine, 7(6), 546-551. https://doi.org/10.3736/jcim20090610.

Luis, A. P., Claudia, A. P., Eduardo, S. C., \& Misael, C. (2011). Physalis peruviana Linnaeus, the multiple properties of a highly functional fruit: A review. Food Research International, 44(7), 1733-1740.

Mallhi, T. H., Qadir, M. I., Khan, Y. H., \& Ali, M. (2014). Hepatoprotective activity of aqueous methanolic extract of Morus nigra against paracetamol-induced hepatotoxicity in mice. Bangladesh Journal of Pharmacology, 9, 60-66.

Memon, A. A., Memon, N., Luthria, D. L., Bhanger, M. I., \& Pitafi, A. A. (2010). Phenolic acid profiling and antioxidant potential of mulberry (Morus laevigata, Morus nigra and Morus alba L.) leaves and fruits grown in Pakistan. Polish Journal of Food and Nutrition Sciences, 60(1), 25-32.

Merfort, I., Wray, V., Barakat, H., Hussein, S., Nawwar, M., \& Willuhn, G. (1997). Flavonoid triglycerides from seeds of Nigella sativa. Phytochemistry, 46, 359-363.

Montgomery, H. A. C., \& Dymock, J. F. (1961). The determination of nitrite in water. Analyst, 86, 414-416.

Moschen, A. R., Wieser, V., \& Tilg, H. (2012). Adiponectin: Key player in the adipose tissue-liver crosstalk. Current Medicinal Chemistry, 19(32), 5467-5473. https:// doi.org/10.2174/092986712803833254.

Muriel, P., Moreno, M.G., Hernández Mdel, C., Chávez, E, Alcantar, L.K. (2015). Resolution of liver fibrosis in chronic $\mathrm{CCl} 4$ administration in the rat after discontinuation of treatment: effect of silymarin, silibinin, colchicine and trimethylcolchicinic acid. Basic \& Clinical Pharmacology \& Toxicology, 96(5), 375-380.

Murray, R. (1984). Aspartate aminotransferase. In A. Kaplan et al. (Eds.), Clinical chemistry, (pp. 1112-1116). The CV Mosby Co.

Ohkawa, H., Ohishi, W., \& Yagi, K. (1979). Analytical Biochemistry, 95, 351.

Paglia, D. E., \& Valentine, W. N. (1967). Studies on the quantitative and qualitative characterization of erythrocyte glutathione peroxidase. The Journal of Laboratory and Clinical Medicine, 70(1), 158-169.

Parola, M., \& Robino, G. (2001). Oxidative stress-related molecules and liver fibrosis. Journal of Hepatology, 35, 297-306.

Peng, X. D., Dai, L. L., Huang, C. Q., He, C. M., Yang, B., \& Chen, L. J. (2009). Relationship between the anti-fibrotic effect of Panax notoginseng saponins and serum cytokines in rat hepatic fibrosis. Biochemical and Biophysical
Research Communications, 388(1), 31-34. https://doi.org/10.1016/j.bbrc.2009. 07.099.

Rajesh, M., \& Latha, M. (2004). Preliminary evaluation of the antihepatotoxic activity of Kamilari, a polyherbal formulation. Journal of Ethnopharmacology, 91(1), 99-104. https://doi.org/10.1016/j.jep.2003.12.011.

Ramadan, M. F. (2011). Physalis peruviana: A rich source of bioactive phytochemicals for functional foods and pharmaceuticals. Food Reviews International, 27(3), 259-273.

Riddle, E. S., Campbell, M. S., Lang, B. Y., Bierer, R., Wang, Y., Bagley, H. N., \& JossMoore, L. A. (2014). Intrauterine growth restriction increases TNF alpha and activates the unfolded protein response in male rat pups. Journal of Obesity, $2014,829862$.

Ross, J. A., \& Kasum, C. M. (2002). Dietary flavonoids: Bioavailability, metabolic effects, and safety. Annual Review of Nutrition, 22(1), 19-34. https://doi.org/1 0.1146/annurev.nutr.22.111401.144957.

Sakanaka, S., Tachibana, Y., \& Okada, Y. (2005). Preparation and antioxidant properties of extracts of Japanese persimmon leaf tea (kakinohacha). Food Chemistry, 89, 569-575.

Salcedo, E. M., Sendra, E., Barrachina, A. A., Martínez, J. J., \& Hernández, F. (2016). Fatty acids composition of Spanish black (Morus nigra L.) and white (Morus alba L.) mulberries. Food Chemistry, 190, 566-571.

Sansoè, G., Aragno, M., Mastrocola, R., Mengozzi, G., Novo, E., \& Parola, M. (2016). Role of chymase in the development of liver cirrhosis and its complications: Experimental and human data. PLoS One, 11, e0162644.

Sathyadevi, M.. \& Subramanian, S. (2015). Extraction, isolation, and characterization of bioactive flavonoids from the fruits of Physalis peruviana Linn extract. Asian Journal of Pharmaceutical and Clinical Research, 8(1), 152-157.

Saxena, P. N., Rathor, S., Mahour, K., Saxena, N., \& Bajaj, P. (2010). Alterations in hepatosomatic index and behaviour under stress of arsenic trioxide and their modulation by curcuma Aromatica plant extract in albino rats (Berkhout). Pharmacologyonline., 1, 243-251.

Shahidi, F., \& Zhong, Y. (2010). Lipid oxidation and improving the oxidative stability. Chemical Society Reviews, 39(11), 4067-4079. https://doi.org/10.1039/b922183m.

Soares, M. B., Brustolim, D., Santos, L. A., Bellintani, M. C., Paiva, F. P., Ribeiro, Y. M., ... Ribeiro Dos Santos, R. (2006). Physalins B, F, and G, seco-steroids purified from Physalis angulata L., inhibit lymphocyte function and allogeneic transplant rejection. International Immunopharmacology, 6(3), 408-414. https://doi.org/10.1016/j.intimp.2005.09.007.

Sun, X. F., Zhang, H. N. F. K. B., \& NFKBI (2007). Polymorphisms in relation to susceptibility of tumors and other diseases. Histology and Histopathology, 22(12), 1387-1398. https://doi.org/10.14670/HH-22.1387.

Taj, D., Khan, H., Sultana, V., Ara, J., \& Ehteshamul-Haque, S. (2014). Antihepatotoxic effect of goldenberry (Physalis peruviana Linn.) in carbon tetrachloride (CCI4) intoxicated rats. Pakistan Journal of Pharmaceutical Sciences, 27(3), 491-494.

Tatsimo, S. J. N., Tamokou, J. D. D. D., Havyarimana, L., et al. (2012). Antimicrobial and antioxidant activity of kaempferol rhamnoside derivatives from Bryophyllum pinnatum. BMC Research Notes, 5(1), 158. https://doi.org/10.11 86/1756-0500-5-158.

Tipoe, G. L., Leung, T. M., Liong, E. C., Lau, T. Y. H., Fung, M. L., \& Nanji, A. A. (2010). Epigallocatechin-3-gallate (EGCG) reduces liver inflammation, oxidative stress, and fibrosis in carbon tetrachloride (CC/4)-induced liver injury in mice. Toxicology., 273(1-3), 45-52. https://doi.org/10.1016/j.tox.2010.04.014.

Wahid, A., Hamed, A. N., Eltahir, H. M., \& Abouzied, M. M. (2016). Hepatoprotective activity of ethanolic extract of Salix subserrata against CCl4- induced chronic hepatotoxicity in rats. BMC Complementary and Alternative Medicine, 16(1), 263. https://doi.org/10.1186/s12906-016-1238-2.

Weiler-Normann, C., Herkel, J., \& Lohse, A. W. (2007). Mouse models of liver fibrosis. Zeitschrift für Gastroenterologie, 45(1), 43-50. https:/doi.org/10.1055/s-2006-927387.

Wu, S. J., Ng, L. T., Lin, D. L., Huang, S. N., Wang, S. S., \& Lin, C. C. (2004). Physalis peruviana extract induces apoptosis in human Hep G2 cells through CD95/ CD95L system and the mitochondrial signaling transduction pathway. Cancer Letters, 215(2), 199-208. https://doi.org/10.1016/j.canlet.2004.05.001.

Wu, S. J., Tsai, J. Y., Chang, S. P., Lin, D. L., Wang, S. S., Huang, S. N., \& Ng, L. T. (2006). Supercritical carbon dioxide extract exhibits enhanced antioxidant and anti-inflammatory activities of Physalis peruviana. Journal of Ethnopharmacology, 108(3), 407-413. https://doi.org/10.1016/j.jep.2006.05.027.

\section{Publisher's Note}

Springer Nature remains neutral with regard to jurisdictional claims in published maps and institutional affiliations. 